OPEN ACCESS

Edited by:

Marco Rossi,

University of Catanzaro, Italy

Reviewed by:

Luca Filippi,

University of Florence, Italy

Massimo Dal Monte,

University of Pisa, Italy

${ }^{*}$ Correspondence:

Anand Krishnan

anand.krishnan@usask.ca

Specialty section:

This article was submitted to Cancer Molecular Targets and

Therapeutics,

a section of the journal

Frontiers in Oncology

Received: 15 March 2020

Accepted: 20 April 2020

Published: 13 May 2020

Citation:

Bautista M and Krishnan A (2020) The Autonomic Regulation of Tumor

Growth and the Missing Links.

Front. Oncol. 10:744

doi: $10.3389 /$ fonc. 2020.00744

\section{The Autonomic Regulation of Tumor Growth and the Missing Links}

\author{
Maricris Bautista $^{1,2}$ and Anand Krishnan ${ }^{1,2 *}$ \\ ${ }^{1}$ Department of Anatomy, Physiology, and Pharmacology, College of Medicine, University of Saskatchewan, Saskatoon, SK, \\ Canada, ${ }^{2}$ Cameco MS Neuroscience Research Centre (CMSNRC), University of Saskatchewan, Saskatoon, SK, Canada
}

Accumulating evidence now indicates that peripheral nerves and solid tumors mutually support the growth of each other. Tumor-derived molecular cues guide nerve infiltration to the tumor milieu, while the tumor-infiltrating nerves provide molecular support to promote tumor growth and dissemination. In this mini-review, we discuss the unique roles of sympathetic and parasympathetic nerves in promoting tumor growth and metastasis. The contribution of adrenergic and cholinergic signals, the specific receptors involved, and the downstream molecular links in both cancer cells and stromal cells are discussed for their intrinsic capacity to modulate tumor growth. We identified unappreciated niche areas in the field, an investigation of which are critical to filling the knowledge gap in understanding the biology of neuromodulation of cancers.

Keywords: nerve-tumor interface, nerve-tumor crosstalk, nerve-dependence of cancers, metastasis, norepinephrine, acetylcholine, neurotrophic factors

\section{INTRODUCTION}

The tumor microenvironment significantly influences the progression of solid tumors (1). Therefore, there has been a long-standing interest in understanding the functions of stromal cells in the tumor milieu. An immense interest has been recently developed in understanding the functions of peripheral nerves in the tumor microenvironment. For many decades, nerves were only recognized as pain carriers of tumors. However, recent studies demonstrated that peripheral nerves modulate tumor growth and dissemination. The widely recognized belief now is that the tumors attract nerves by stimulating nerve growth, and in turn, the nerves feed both cancer and stromal cells in the tumor milieu $(2,3)$.

The nerve-derived molecules supporting tumor growth have been reviewed in much detail $(2,3)$. In this regard, the neurotransmitters released from autonomic nerves have gained much attention, and clinical trials are now underway by blocking the corresponding receptors to managing a variety of solid tumors. Here, we review the nerve-tumor interface with particular attention to the unique contribution of autonomic signaling to tumor growth and dissemination. We also discuss the missing links in the current state of knowledge in understanding the biology of neuromodulation of cancers.

\section{THE NERVE-TUMOR CROSSTALK: THE MILESTONES}

The nerve-dependence of tumors received initial attention due to the occurrence of perineural invasion (PNI), in which cancer cells migrate around and invade nerves (4-6). Although PNI was recognized much earlier as a complex physical interaction between cancer cells and nerves, a mutual growth stimulatory interaction between the cancer cells and neurons was experimentally demonstrated within the past two decades. In an elegant study, Ayala et al. showed that the 
outgrowth and directionality of sensory neurons and the proliferation and migration of prostate cancer cells were mutually benefitted when they were cultured together (7). This observation kickstarted serious investigations to understanding the nervetumor interface.

In the early 2000, clinicians also found an association between underlying stress and poor prognosis of cancer patients (8). Supporting this association, a study by Thaker et al. showed that stress-activated adrenergic signals promote tumor growth, signifying the critical involvement of sympathetic nerves in tumor progression (9). Another breakthrough occurred in 2013 when Magnon et al. demonstrated that adrenergic signals in stromal cells are indeed essential for tumorigenesis (10). The tumor promoting roles of cholinergic signals were also established around this time when it was discovered that cholinergic muscarinic receptors facilitate tumorigenesis and metastasis $(10,11)$. These discoveries then fuelled a broader interest in understanding the roles of autonomic signals in tumor microenvironment.

\section{SYMPATHETIC DISTRIBUTION IN THE TUMOR MICROENVIRONMENT}

Sympathetic nerve innervation in tumors has been demonstrated in prostate, ovarian, and breast tumors by specifically staining the adrenergic neurons with tyrosine hydroxylase (10, 1214). In addition, animal tumor models of the prostate, melanoma and ovarian cancers showed increased levels of the sympathetic neurotransmitter norepinephrine (NE), indicating that sympathetic activity is enhanced in solid tumors $(12,13,15)$. $\mathrm{NE}$ has also been implicated in stress-mediated melanoma and ovarian tumor progression $(13,16)$. The specific receptors for NE, the adrenergic $\beta$ receptors $(\operatorname{Adr} \beta)$, are widely distributed in both cancer and stromal cells. For example, the $\operatorname{Adr} \beta$ are expressed in the prostate, melanoma, ovarian, pancreatic, colon and breast cancer cells, and pericytes, endothelial cells, lymphocytes, and myeloid cells $(10,12-14,17-22)$. Among the $\operatorname{Adr} \beta$, varying expressions and levels of $\operatorname{Adr} \beta 1 / \beta 2 / \beta 3$ are reported in several cancer types (23).

\section{ADRENERGIC SIGNALS AS TUMOR PROMOTERS: MOLECULAR MECHANISMS}

Several growth signaling cascades are activated downstream of Adr $\beta$. For example, Adr $\beta 2$ activation was shown to trigger Src kinase to promote ovarian cancer cell proliferation, migration, and invasion (19). A positive association between NE and Src activation was also demonstrated in human ovarian tumors substantiating the tumor promoting roles of the NE-Src axis (19). Adr $\beta 2$ also enables cancer cells to escape chemotherapyinduced cytotoxicity. For instance, $\operatorname{Adr} \beta 2$ signals have shown to activate the survival phosphatase, DUSP1, which in turn dephosphorylates JNK and c-jun to promote ovarian cancer cell survival pre-treated with cisplatin or paclitaxel (24). Thaker et al. showed that activation of Adr $\beta 2$ by NE induces VEGF in ovarian cancer cells (9). The VEGF, in turn, signals endothelial cells to facilitate angiogenesis, which is an example of how NE promotes tumor angiogenesis indirectly (9). Interestingly, NE dependent activation of $\operatorname{Adr} \beta 3$ in ovarian cancer cells induces BDNF through cAMP/JNK activation (13). The BDNF then signals $\mathrm{TrKB}$ receptors in the nearby nerves to promote axonogenesis, which is an example of how NE promotes tumor axonogenesis indirectly. A positive association between NE and BDNF was also observed in human ovarian carcinoma, further indicating that the NE-BDNF axis promotes tumors (13).

The tumor-promoting roles of $\mathrm{Adr} \beta 3$, and the mechanisms involved, have been extensively studied in melanoma. In line with this, Dal Monte et al. showed that blockade of $\operatorname{Adr} \beta 3$ induces apoptosis of melanoma cells through downregulation iNOS (inducible nitric oxide synthase) mediated NO synthesis $(25,26)$. Calvani et al. showed that various cellular stresses, such as hypoxia, ischemia, or glucose deprivation induce $\operatorname{Adr} \beta 3$ in melanoma cells, suggesting that these natural triggers may drive higher production of $\operatorname{Adr} \beta 3$ in the tumor milieu (21). Strikingly, Adr $\beta 3$ promotes the classical Warburg effect (preferred glycolysis) in melanoma stem cells by upregulating UCP2 (uncoupling protein 2) (27). Adr $\beta 3$ was also shown to regulate the stemness of neuroblastoma cells wherein $\mathrm{Adr} \beta 3$ inhibition promoted their differentiation by disrupting the sphingosine kinase 2(sk2)-sphingosine-1-phosphatase receptor 2 (S1P2) axis, which is a lipid metabolic axis otherwise crucial for these cells' stemness and proliferation (28).

The Adr $\beta$ have stromal cell-specific actions too. Selective depletion of $\operatorname{Adr} \beta 2$ and/or $\operatorname{Adr} \beta 3$ in the stromal compartment prevented the occurrence and early growth of prostate cancer, indicating that stromal cell-specific $\operatorname{Adr} \beta$ is essential for maturation of oncogenic signals (10). $\operatorname{Adr} \beta 2$ also facilitates aerobic glycolysis in endothelial cells and promote tumor angiogenesis (12). Both $\mathrm{CD}^{+}$and $\mathrm{CD}^{+} \mathrm{T}$ lymphocytes express $\operatorname{Adr} \beta 2$, while sympathetic deprivation of these cells downregulates the immune checkpoint protein PD-1 and favor better immune surveillance of breast cancer (14). The $\operatorname{Adr} \beta 3$ is also expressed in stromal cells, especially fibroblasts, endothelial cells, and immune cells and support tumors and angiogenesis $(21,29)$. Specific blockade of $\operatorname{Adr} \beta 3$ was shown to impair endothelial cell survival in melanoma (25). Besides, blockade of $\operatorname{Adr} \beta 3$ was shown to accentuate the levels of cytotoxic $\mathrm{T}$ lymphocytes and natural killer (NK) cells and attenuate the levels of tumor favoring regulatory $\mathrm{T}$ cells (Tregs) and myeloid-derived suppressor cells (MDSCs) in melanoma, promoting a favorable immune surveillance (29). Interestingly, $\operatorname{Adr} \beta 3$ inhibition in myeloid cells switches macrophage and neutrophil phenotypes to immunocompetent $\mathrm{M} 1$ and $\mathrm{N} 1$ types, respectively, indicating additional mechanisms of $\mathrm{Adr} \beta 3$ blockers in checking tumors (29). Adr $\beta 3$ signals also enrich stromal population by recruiting and maintaining hemopoietic (HSC) and mesenchymal stem cells (MSC) favoring tumor aggression, while $\operatorname{Adr} \beta 3$ blockade was shown to promote local differentiation of HSC to lymphoid/myeloid lineages and MSC to adipocyte lineages in melanoma favoring a less aggressive tumor milieu (30).

The adrenergic signals also promote migration and invasion of cancer cells. Activation of $\operatorname{Adr} \beta$ in ovarian and pancreatic 


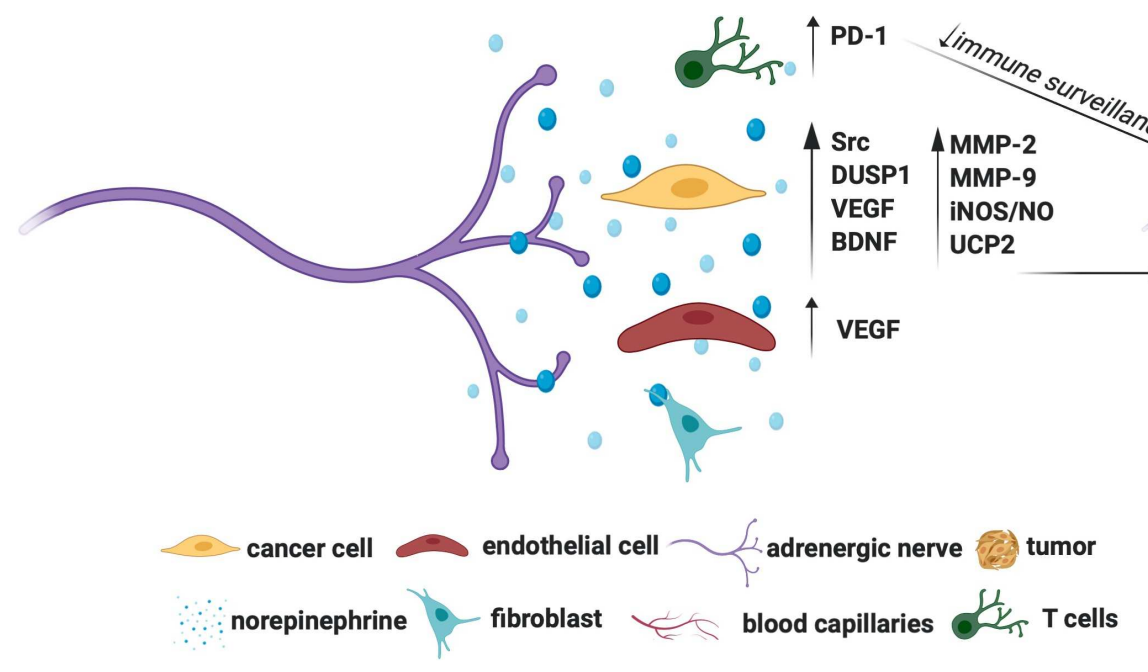

FIGURE 1 | Molecular mechanisms for the tumor promoting actions of adrenergic signals.

cancer cells upregulates MMP-2, MMP-9 and VEGF to facilitate cell migration and invasion $(18,31)$. A phase II trial showed that a combination of propranolol (a non-specific Adr $\beta$ blocker) and etodolac (a non-steroidal anti-inflammatory drug) reduces the levels of epithelial-mesenchymal transition (EMT) genes involved with breast cancer metastasis, suggesting a potential clinical benefit of using $\beta$-blockers in fighting metastasis (32). This trial also showed immune profile changes in the treatment cohort (32). However, due to the combined treatment protocol used in this trial, the exact contribution of $\beta$-blockers in generating this gene profile is not known. Nonetheless, retrospective analyses showed that $\beta$-blockers slow down the progression of multiple myeloma, prostate, melanoma, lung, and ovarian cancers, indicating an apparent additional benefit of targeting adrenergic signals for prolonging disease-free survival (33-37).

Overall, $\operatorname{Adr} \beta$ receptors, especially the $\operatorname{Adr} \beta 2$ and $\operatorname{Adr} \beta 3$, show promise as cancer therapeutic targets. The molecular mechanisms by which adrenergic signals promote tumor growth are summarized in Figure 1. However, it remains to be established whether targeting $\operatorname{Adr} \beta$ is beneficial in treating all cancer types. For example, inhibition of $\operatorname{Adr} \beta 2$ showed no effect in gastric tumors (38). Moreover, although NE levels were shown to increase in animal tumors, such an increase in its levels was established only in human ovarian carcinoma (13). Quantification of NE in other tumor types also is warranted to identify its general activation profile in human cancers. Similarly, although $\operatorname{Adr} \beta 3$ was shown to maintain stem cell traits in tumor milieu, more understanding is required to elucidate the responsible mechanisms.

\section{PARASYMPATHETIC DISTRIBUTION IN THE TUMOR MICROENVIRONMENT}

In contrast to sympathetic signals, the parasympathetic signals offer both tumor suppressing and promoting functions. The parasympathetic innervation has been demonstrated in gastric, prostate and breast cancers using choline acetyltransferase (ChaT) or vesicular acetylcholine transporter (VAchT) as specific markers $(10,14,38)$. The specific receptors of the parasympathetic neurotransmitter acetylcholine, the cholinergic muscarinic receptors (Chrms), are shown to express in gastric, pancreatic, lung, cervical, and colon cancer cells (38-42). Interestingly, lung, pancreatic, cervical and colon cancer cells, and gastric epithelial tuft cells express acetylcholine, independent of nerves $(38,40,43)$.

\section{CHOLINERGIC SIGNALS AS TUMOR SUPPRESSORS: MOLECULAR MECHANISMS}

Early studies in the ' 80 s showed that cholinergic deprivation resulting from vagotomy facilitates gastric tumorigenesis, suggesting that cholinergic signals are essential for tumor suppression (44, 45). Similarly, a recent study by Renz et al. showed that vagotomy promotes pancreatic tumor progression whereas selective activation of Chrm 1 reduced tumor incidence (42). Using RNA sequencing studies, the authors showed that Chrm1 signals perturb EGFR/MAPK and PI3K/AKT cascade in cancer cells to inhibit tumor growth (42). Chrm1 activation was also shown to suppress cancer stem cells (CSCs), which is an additional mechanism by which cholinergic signals suppress tumors (42).

The cholinergic signals also modulate the neuro-immune axis. In line with this, Dubeykovskaya et al. showed that cholinergic activation induces trefoil factor 2 (TFF2) secretion by memory $\mathrm{T}$ cells, which in turn suppresses MDSC to prevent colorectal cancer progression (46). Similarly, Kamia et al. showed that parasympathetic stimulation of T lymphocytes, which express Chrm1, reduces the immune checkpoint protein $\mathrm{PD}-1$, leading to suppression of breast cancer (14). The cholinergic-immune axis is also essential for suppressing pancreatic cancer. For instance, 


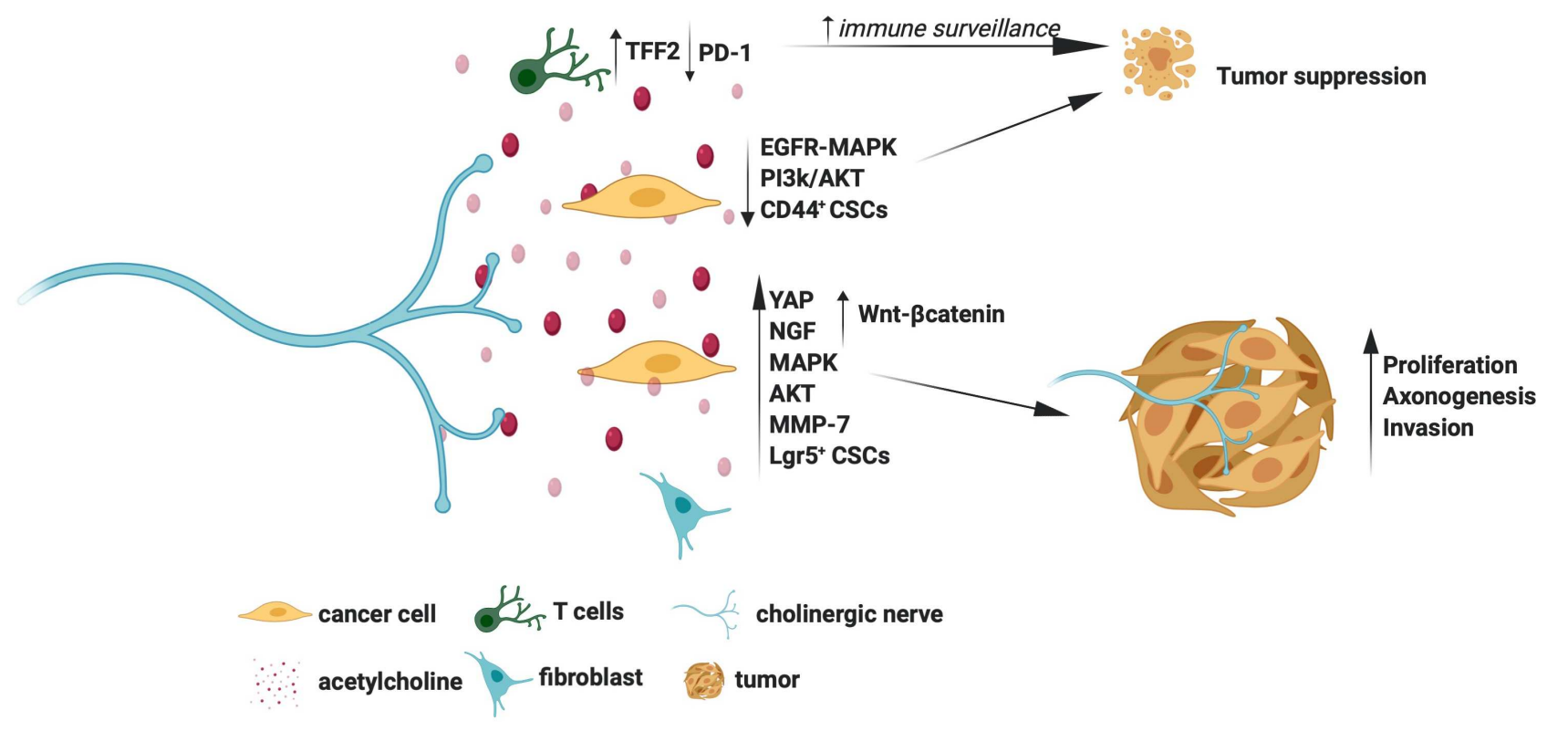

FIGURE 2 | Molecular mechanisms for the tumor promoting and suppressing actions of cholinergic signals.

cholinergic deprivation was shown to increase macrophage influx and production of $\mathrm{TNF} \alpha$, resulting in pancreatic tumor progression (47).

\section{CHOLINERGIC SIGNALS AS TUMOR PROMOTERS: MOLECULAR MECHANISMS}

Through selective depletion studies, Zhao et al. demonstrated that a lack of cholinergic transmission prevents gastric tumorigenesis, while Magnon et al. showed that the lack of these signals in stromal cells prevents prostate cancer metastasis $(10,11)$. There are multiple mechanisms that account for the tumor promoting actions of cholinergic signals. For instance, in gastric cancer cells, activated Chrm 3 induces Wnt- $\beta$-catenin signals downstream of the transcriptional co-activator YAP (38). The Wnt- $\beta$-catenin signals then expand cancer stem cells (CSCs) to promote gastric tumor growth (11). Chrm3 was also shown to induce NGF in gastric cancer cells, and the NGF then acts on TrkA receptors in the nearby nerves to facilitate tumor innervation, which is an example of how cholinergic signals promote tumor axonogenesis indirectly (38). Expression of NGF and YAP was also associated with advanced stages of gastric tumors, which further substantiates the critical roles of Chrm3-NGF and Chrm3-YAP axes in tumor pathology (38). A retrospective study showed that vagotomy, and associated cholinergic deprivation, reduces gastric cancer incidence, suggesting a potential utility of cholinergic blockers in preventing gastric cancers (11). Chrm3 was also shown to promote Small Cell Lung Carcinoma (SCLC) by activating MAPK and Akt signals (40). Chrm3 promotes the invasion of cancer cells too. For instance, Chrm3 was shown to activate ERBB receptors downstream of MMP-7 in colon cancer cells, which, in turn, triggered MAPK and Akt signaling to induce cell invasion (41). Besides, inhibition of Chrm3 was shown to attenuate small intestinal neoplasia, further confirming the therapeutic utility of Chrm3 blockers in intestinal cancers (48).

In contrast to the findings by Renz et al., which showed that Chrm1 suppresses pancreatic cancer, a study by Magnon et al. showed that stromal cells-specific Chrm1 is indeed essential for prostate cancer metastasis, indicating that Chrm1 is a potential therapeutic target for prostate cancer $(10,42)$. A study by Coarfa et al. also supported the idea that cholinergic blockers are effective in prostate cancer by demonstrating that Botox mediated depletion of cholinergic signals improves prostate cancer outcomes (49).

The molecular mechanisms by which cholinergic signals promote or suppress tumors are summarized in Figure 2. Overall, the Chrms, especially the Chrm1 and Chrm3, appear as promising targets for cancer therapy. However, it is still puzzling how the cholinergic signals elicit contrasting effects in tumors, for example, they promote and suppress gastric and pancreatic cancers, respectively $(11,38,42)$. The wide expression of Chrms in cancer and stromal cells and the nerve-independent sources of acetylcholine pose hurdles in selectively studying the contribution of cholinergic nerves in tumors. Understanding of the distribution pattern of Chrms sub-types, and the various sources of acetylcholine in specific tumor types would further delineate the unique contribution of cholinergic signals in distinct tumors.

\section{DISCUSSION AND FUTURE PERSPECTIVES}

Accumulating evidence beyond doubt indicates that nerves offer trophic support to adult tissues. For instance, nerves maintain the 
adult stem cell niche, participate in wound healing, and facilitate regeneration of adult tissues (50-54). While nerves execute these functions in a controlled manner-they know when to outset and dismiss trophic secretions-it seems it is not the case when they encounter tumors, although more studies are required to make definite conclusions. No studies, however, claim that nervederived signals on its own are tumorigenic, but instead amplify an underlying tumor pathology $(10,11,38,42)$.

Landmark studies that addressed nerve-dependence of tumors used experimental denervation to show that lack of nerves prevents tumorigenesis $(10,11)$. However, the pathophysiological consequences that follow nerve damage has not been taken into account in these studies. For instance, peripheral nerve injury leads to Wallerian degeneration of nerves, recruitment of myeloid cells, and initiation of Schwann cell (SC) proliferation (55). These functional consequences may hinder experimental tumorigenesis. For instance, vagotomy was shown to induce chemokine signaling and leukocytes recruitment, similar to that occur during Wallerian degeneration, in gastric tumors (11). Denervation also induces extensive genotypic changes in healthy tissues (49). Therefore, denervation studies may be interpreted with caution when defining the mechanisms of nerve dependence of cancers.

Adult tissue function and homeostasis are maintained by coordinated actions of autonomic, sensory, and motor neurons. Therefore, a more holistic approach of considering the roles of both sensory and autonomic nerves will give additional insights into the overall effects of peripheral nerves on tumor dynamics. Sensory neurons are likely the first responders to changes in the local environment, and therefore, it is critical to understand

\section{REFERENCES}

1. Bussard KM, Mutkus L, Stumpf K, Gomez-Manzano C, Marini FC. Tumorassociated stromal cells as key contributors to the tumor microenvironment. Breast Cancer Res. (2016) 18:84. doi: 10.1186/s13058-016-0740-2

2. Jobling P, Pundavela J, Oliveira SM, Roselli S, Walker MM, Hondermarck H. Nerve-cancer cell cross-talk: a novel promoter of tumor progression. Cancer Res. (2015) 75:1777-81. doi: 10.1158/0008-5472.Can-14-3180

3. Boilly B, Faulkner S, Jobling P, Hondermarck H. Nerve dependence: from regeneration to cancer. Cancer Cell. (2017) 31:342-54. doi: 10.1016/j.ccell.2017.02.005

4. Villers A, McNeal JE, Redwine EA, Freiha FS, Stamey TA. The role of perineural space invasion in the local spread of prostatic adenocarcinoma. $J$ Urol. (1989) 142:763-8. doi: 10.1016/s0022-5347(17)38881-x

5. Li R, Wheeler T, Dai H, Ayala G. Neural cell adhesion molecule is upregulated in nerves with prostate cancer invasion. Hum Pathol. (2003) 34:457-61. doi: 10.1016/s0046-8177(03)00084-4

6. Shimada K, Nara S, Esaki M, Sakamoto Y, Kosuge T, Hiraoka N. Intrapancreatic nerve invasion as a predictor for recurrence after pancreaticoduodenectomy in patients with invasive ductal carcinoma of the pancreas. Pancreas. (2011) 40:464-8. doi: 10.1097/MPA.0b013e31820b5d37

7. Ayala GE, Wheeler TM, Shine HD, Schmelz M, Frolov A, Chakraborty S, et al. In vitro dorsal root ganglia and human prostate cell line interaction: redefining perineural invasion in prostate cancer. Prostate. (2001) 49:213-23. doi: $10.1002 /$ pros. 1137

8. Ben-Eliyahu S. The promotion of tumor metastasis by surgery and stress: immunological basis and implications for psychoneuroimmunology. Brain Behav Immun. (2003) 17 Suppl 1:S27-36. doi: 10.1016/s0889-1591(02)00063-6 how these neurons respond to malignant proliferation. We found that sensory neurons promote proliferation of mature macrophages and glial cells (56). Sensory nerves are also rich source of growth factors, such as NGF, BDNF, and GDNF, and interestingly, several studies demonstrated tumor-specific expression of these growth factors and their receptors $(13,38$, 57). Sensory neurons also express tumor suppressor proteins and DNA repair proteins, indicating that they are equipped with tumor suppressor machinery too (58-60). Although both tumor promoting and suppressing roles are attributed to sensory neurons, more studies are required in this direction to make definite conclusions (61-63). Finally, while most studies demonstrated nerve innervation in human tumor samples, a future examination of differential distribution of sympathetic, parasympathetic, and sensory neurons may provide additional insights into whether adrenergic, cholinergic, or sensory nerve on its own is tumor permissive or suppressive.

\section{AUTHOR CONTRIBUTIONS}

MB participated in developing the concept, collected the literature, and composed the preliminary draft. AK formulated the concept, revised the draft extensively, composed the figures, and finalized the manuscript.

\section{ACKNOWLEDGMENTS}

College of Medicine, and Office of the Vice-Provost, Faculty Relations, University of Saskatchewan for the Research start-up fund to AK.
9. Thaker PH, Han LY, Kamat AA, Arevalo JM, Takahashi R, Lu C, et al. Chronic stress promotes tumor growth and angiogenesis in a mouse model of ovarian carcinoma. Nat Med. (2006) 12:939-44. doi: 10.1038/nm1447

10. Magnon C, Hall SJ, Lin J, Xue X, Gerber L, Freedland SJ, et al. Autonomic nerve development contributes to prostate cancer progression. Science. (2013) 341:1236361. doi: 10.1126/science.1236361

11. Zhao CM, Hayakawa Y, Kodama Y, Muthupalani S, Westphalen CB, Andersen GT, et al. Denervation suppresses gastric tumorigenesis. Sci Transl Med. (2014) 6:250ra115. doi: 10.1126/scitranslmed.3009569

12. Zahalka AH, Arnal-Estape A, Maryanovich M, Nakahara F, Cruz CD, Finley LWS, et al. Adrenergic nerves activate an angio-metabolic switch in prostate cancer. Science. (2017) 358:321-6. doi: 10.1126/science.aah5072

13. Allen JK, Armaiz-Pena GN, Nagaraja AS, Sadaoui NC, Ortiz T, Dood R, et al. Sustained Adrenergic signaling promotes intratumoral innervation through BDNF induction. Cancer Res. (2018) 78:3233-42. doi: 10.1158/0008-5472.Can-16-1701

14. Kamiya A, Hayama Y, Kato S, Shimomura A, Shimomura T, Irie K, et al. Genetic manipulation of autonomic nerve fiber innervation and activity and its effect on breast cancer progression. Nat Neurosci. (2019) 22:1289-305. doi: 10.1038/s41593-019-0430-3

15. Sereni F, Dal Monte M, Filippi L, Bagnoli P. Role of host beta1- and beta2-adrenergic receptors in a murine model of B16 melanoma: functional involvement of beta3-adrenergic receptors. Naunyn Schmiedebergs Arch Pharmacol. (2015) 388:1317-31. doi: 10.1007/s00210-015-1165-7

16. Sanzo M, Colucci R, Arunachalam M, Berti S, Moretti S. Stress as a possible mechanism in melanoma progression. Dermatol Res Pract. (2010) 2010:483493. doi: 10.1155/2010/483493

17. Perrone MG, Notarnicola M, Caruso MG, Tutino V, Scilimati A. Upregulation of beta3-adrenergic receptor mRNA in human colon 
cancer: a preliminary study. Oncology. (2008) 75:224-9. doi: 10.1159/0001 63851

18. Guo K, Ma Q, Wang L, Hu H, Li J, Zhang D, et al. Norepinephrine-induced invasion by pancreatic cancer cells is inhibited by propranolol. Oncol Rep. (2009) 22:825-30. doi: 10.3892/or_00000505

19. Armaiz-Pena GN, Allen JK, Cruz A, Stone RL, Nick AM, Lin YG, et al. Src activation by beta-adrenoreceptors is a key switch for tumour metastasis. Nat Commun. (2013) 4:1403. doi: 10.1038/ncomms2413

20. Moretti S, Massi D, Farini V, Baroni G, Parri M, Innocenti S, et al. betaadrenoceptors are upregulated in human melanoma and their activation releases pro-tumorigenic cytokines and metalloproteases in melanoma cell lines. Lab Invest. (2013) 93:279-90. doi: 10.1038/labinvest.2012.175

21. Calvani M, Pelon F, Comito G, Taddei ML, Moretti S, Innocenti S, et al. Norepinephrine promotes tumor microenvironment reactivity through beta3-adrenoreceptors during melanoma progression. Oncotarget. (2015) 6:4615-32. doi: 10.18632/oncotarget.2652

22. Choy C, Raytis JL, Smith DD, Duenas M, Neman J, Jandial R, et al. Inhibition of beta2-adrenergic receptor reduces triple-negative breast cancer brain metastases: the potential benefit of perioperative beta-blockade. Oncol Rep. (2016) 35:3135-42. doi: 10.3892/or.2016.4710

23. Rains SL, Amaya CN, Bryan BA. Beta-adrenergic receptors are expressed across diverse cancers. Oncoscience. (2017) 4:95-105. doi: 10.18632/oncoscience.357

24. Kang Y, Nagaraja AS, Armaiz-Pena GN, Dorniak PL, Hu W, Rupaimoole $\mathrm{R}$, et al. Adrenergic stimulation of DUSP1 impairs chemotherapy response in ovarian cancer. Clin Cancer Res. (2016) 22:1713-24. doi: 10.1158/1078-0432.Ccr-15-1275

25. Dal Monte M, Casini G, Filippi L, Nicchia GP, Svelto M, Bagnoli P. Functional involvement of beta3-adrenergic receptors in melanoma growth and vascularization. J Mol Med. (2013) 91:1407-19. doi: 10.1007/s00109-013-1073-6

26. Dal Monte M, Fornaciari I, Nicchia GP, Svelto M, Casini G, Bagnoli P. beta3-adrenergic receptor activity modulates melanoma cell proliferation and survival through nitric oxide signaling. Naunyn Schmiedebergs Arch Pharmacol. (2014) 387:533-43. doi: 10.1007/s00210-014-0969-1

27. Calvani M, Cavallini L, Tondo A, Spinelli V, Ricci L, Pasha A, et al. beta3-adrenoreceptors control mitochondrial dormancy in melanoma and embryonic stem cells. Oxid Med Cell Longev. (2018) 2018:6816508. doi: 10.1155/2018/6816508

28. Bruno G, Cencetti F, Pini A, Tondo A, Cuzzubbo D, Fontani F, et al. beta3-adrenoreceptor blockade reduces tumor growth and increases neuronal differentiation in neuroblastoma via SK2/S1P2 modulation. Oncogene. (2020) 39:368-84. doi: 10.1038/s41388-019-0993-1

29. Calvani M, Bruno G, Dal Monte M, Nassini R, Fontani F, Casini A, et al. beta3 -Adrenoceptor as a potential immuno-suppressor agent in melanoma. $\mathrm{Br} J$ Pharmacol. (2019) 176:2509-24. doi: 10.1111/bph.14660

30. Calvani M, Bruno G, Dabraio A, Subbiani A, Bianchini F, Fontani F, et al. beta3-Adrenoreceptor blockade induces stem cells differentiation in melanoma microenvironment. Int J Mol Sci. (2020) 21:21041420. doi: 10.3390/ijms21041420

31. Sood AK, Bhatty R, Kamat AA, Landen CN, Han L, Thaker PH, et al. Stress hormone-mediated invasion of ovarian cancer cells. Clin Cancer Res. (2006) 12:369-75. doi: 10.1158/1078-0432.Ccr-05-1698

32. Shaashua L, Shabat-Simon M, Haldar R, Matzner P, Zmora O, Shabtai M, et al. Perioperative COX-2 and beta-adrenergic blockade improves metastatic biomarkers in breast cancer patients in a phase-II randomized trial. Clin Cancer Res. (2017) 23:4651-61. doi: 10.1158/1078-0432.Ccr-17-0152

33. De Giorgi V, Grazzini M, Gandini S, Benemei S, Lotti T, Marchionni $\mathrm{N}$, et al. Treatment with beta-blockers and reduced disease progression in patients with thick melanoma. Arch Intern Med. (2011) 171:779-81. doi: 10.1001/archinternmed.2011.131

34. Diaz ES, Karlan BY, Li AJ. Impact of beta blockers on epithelial ovarian cancer survival. Gynecol Oncol. (2012) 127:375-8. doi: 10.1016/j.ygyno.2012.0 7.102

35. Grytli HH, Fagerland MW, Fossa SD, Tasken KA, Haheim LL. Use of beta-blockers is associated with prostate cancer-specific survival in prostate cancer patients on androgen deprivation therapy. Prostate. (2013) 73:250-60. doi: $10.1002 /$ pros. 22564
36. Wang HM, Liao ZX, Komaki R, Welsh JW, O’Reilly MS, Chang JY, et al. Improved survival outcomes with the incidental use of beta-blockers among patients with non-small-cell lung cancer treated with definitive radiation therapy. Ann Oncol. (2013) 24:1312-9. doi: 10.1093/annonc/mds616

37. Hwa YL, Shi Q, Kumar SK, Lacy MQ, Gertz MA, Kapoor P, et al. Beta-blockers improve survival outcomes in patients with multiple myeloma: a retrospective evaluation. Am J Hematol. (2017) 92:50-5. doi: 10.1002/ajh.24582

38. Hayakawa Y, Sakitani K, Konishi M, Asfaha S, Niikura R, Tomita $\mathrm{H}$, et al. Nerve growth factor promotes gastric tumorigenesis through aberrant cholinergic signaling. Cancer Cell. (2017) 31:21-34. doi: 10.1016/j.ccell.2016.11.005

39. Kodaira M, Kajimura M, Takeuchi K, Lin S, Hanai H, Kaneko E. Functional muscarinic $\mathrm{m} 3$ receptor expressed in gastric cancer cells stimulates tyrosine phosphorylation and MAP kinase. J Gastroenterol. (1999) 34:163-71. doi: $10.1007 / \mathrm{s} 005350050238$

40. Song P, Sekhon HS, Lu A, Arredondo J, Sauer D, Gravett C, et al. M3 muscarinic receptor antagonists inhibit small cell lung carcinoma growth and mitogen-activated protein kinase phosphorylation induced by acetylcholine secretion. Cancer Res. (2007) 67:3936-44. doi: 10.1158/0008-5472.Can-06-2484

41. Belo A, Cheng K, Chahdi A, Shant J, Xie G, Khurana S, et al. Muscarinic receptor agonists stimulate human colon cancer cell migration and invasion. Am J Physiol Gastrointest Liver Physiol. (2011) 300:G749-760. doi: 10.1152/ajpgi.00306.2010

42. Renz BW, Tanaka T, Sunagawa M, Takahashi R, Jiang Z, Macchini M, et al. Cholinergic signaling via muscarinic receptors directly and indirectly suppresses pancreatic tumorigenesis and cancer stemness. Cancer Discov. (2018) 8:1458-73. doi: 10.1158/2159-8290.Cd-18-0046

43. Cheng K, Samimi R, Xie G, Shant J, Drachenberg C, Wade M, et al. Acetylcholine release by human colon cancer cells mediates autocrine stimulation of cell proliferation. Am J Physiol Gastrointest Liver Physiol. (2008) 295:G591-597. doi: 10.1152/ajpgi.00055.2008

44. Tatsuta M, Yamamura H, Iishi H, Ichii M, Noguchi S, Baba M, et al. Promotion by vagotomy of gastric carcinogenesis induced by $\mathrm{N}$-methyl-N'-nitro-Nnitrosoguanidine in Wistar rats. Cancer Res. (1985) 45:194-7.

45. Tatsuta M, Iishi H, Yamamura H, Baba M, Taniguchi H. Effects of bilateral and unilateral vagotomy on gastric carcinogenesis induced by $\mathrm{N}$-methyl$\mathrm{N}$-nitro-N-nitrosoguanidine in Wistar rats. Int J Cancer. (1988) 42:414-8. doi: 10.1002/ijc.2910420318

46. Dubeykovskaya Z, Si Y, Chen X, Worthley DL, Renz BW, Urbanska AM, et al. Neural innervation stimulates splenic TFF2 to arrest myeloid cell expansion and cancer. Nat Commun. (2016) 7:10517. doi: 10.1038/ncomms10517

47. Partecke LI, Kading A, Trung DN, Diedrich S, Sendler M, Weiss F, et al. Subdiaphragmatic vagotomy promotes tumor growth and reduces survival via TNFalpha in a murine pancreatic cancer model. Oncotarget. (2017) 8:2250112. doi: 10.18632/oncotarget.15019

48. Raufman JP, Shant J, Xie G, Cheng K, Gao XM, Shiu B, et al. Muscarinic receptor subtype- 3 gene ablation and scopolamine butylbromide treatment attenuate small intestinal neoplasia in Apcmin/+ mice. Carcinogenesis. (2011) 32:1396-402. doi: 10.1093/carcin/bgr118

49. Coarfa C, Florentin D, Putluri N, Ding Y, Au J, He D, et al. Influence of the neural microenvironment on prostate cancer. Prostate. (2018) 78:128-39. doi: $10.1002 /$ pros. 23454

50. Cheng C, Singh V, Krishnan A, Kan M, Martinez JA, Zochodne DW. Loss of innervation and axon plasticity accompanies impaired diabetic wound healing. PLoS ONE. (2013) 8:e75877. doi: 10.1371/journal.pone.0075877

51. Knox SM, Lombaert IM, Haddox CL, Abrams SR, Cotrim A, Wilson AJ, et al. Parasympathetic stimulation improves epithelial organ regeneration. Nat Commun. (2013) 4:1494. doi: 10.1038/ncomms 2493

52. Rinkevich Y, Montoro DT, Muhonen E, Walmsley GG, Lo D, Hasegawa $\mathrm{M}$, et al. Clonal analysis reveals nerve-dependent and independent roles on mammalian hind limb tissue maintenance and regeneration. Proc Natl Acad Sci USA. (2014) 111:9846-51. doi: 10.1073/pnas.1410097111

53. Tong CK, Chen J, Cebrian-Silla A, Mirzadeh Z, Obernier K, Guinto CD, et al. Axonal control of the adult neural stem cell niche. Cell Stem Cell. (2014) 14:500-11. doi: 10.1016/j.stem.2014.01.014

54. Carr MJ, Toma JS, Johnston APW, Steadman PE, Yuzwa SA, Mahmud N, et al. Mesenchymal precursor cells in adult nerves contribute to mammalian 
tissue repair and regeneration. Cell Stem Cell. (2019) 24:240-56.e249. doi: 10.1016/j.stem.2018.10.024

55. Krishnan A, Duraikannu A, Zochodne DW. Releasing 'brakes' to nerve regeneration: intrinsic molecular targets. Eur J Neurosci. (2016) 43:297-308. doi: 10.1111/ejn.13018

56. Krishnan A, Bhavanam S, Zochodne D. An intimate role for adult dorsal root ganglia resident cycling cells in the generation of local macrophages and satellite glial cells. J Neuropathol Exp Neurol. (2018) 77:929-41. doi: $10.1093 /$ jnen/nly072

57. He S, Chen $\mathrm{CH}$, Chernichenko $\mathrm{N}, \mathrm{He} \mathrm{S}$, Bakst RL, Barajas F, et al. GFRalphal released by nerves enhances cancer cell perineural invasion through GDNF-RET signaling. Proc Natl Acad Sci USA. (2014) 111:E2008-17. doi: 10.1073/pnas.1402944111

58. Christie KJ, Krishnan A, Martinez JA, Purdy K, Singh B, Eaton S, et al. Enhancing adult nerve regeneration through the knockdown of retinoblastoma protein. Nat Commun. (2014) 5:3670. doi: $10.1038 /$ ncomms4670

59. Singh B, Singh V, Krishnan A, Koshy K, Martinez JA, Cheng C, et al. Regeneration of diabetic axons is enhanced by selective knockdown of the PTEN gene. Brain. (2014) 137(Pt 4):1051-67. doi: 10.1093/brain/a wu031

60. Krishnan A, Purdy K, Chandrasekhar A, Martinez J, Cheng C, Zochodne DW. A BRCA1-Dependent DNA damage response in the regenerating adult peripheral nerve milieu. Mol Neurobiol. (2018) 55:4051-67. doi: 10.1007/s12035-017-0574-7

61. Erin N, Duymus O, Ozturk S, Demir N. Activation of vagus nerve by semapimod alters substance $\mathrm{P}$ levels and decreases breast cancer metastasis. Regul Pept. (2012) 179:101-8. doi: 10.1016/j.regpep.2012.08.001

62. Peterson SC, Eberl M, Vagnozzi AN, Belkadi A, Veniaminova NA, Verhaegen $\mathrm{ME}$, et al. Basal cell carcinoma preferentially arises from stem cells within hair follicle and mechanosensory niches. Cell Stem Cell. (2015) 16:400-12. doi: 10.1016/j.stem.2015.02.006

63. Sinha S, Fu YY, Grimont A, Ketcham M, Lafaro K, Saglimbeni JA, et al. PanIN neuroendocrine cells promote tumorigenesis via neuronal cross-talk. Cancer Res. (2017) 77:1868-79. doi: 10.1158/0008-5472.Can-16-0899-t

Conflict of Interest: The authors declare that the research was conducted in the absence of any commercial or financial relationships that could be construed as a potential conflict of interest.

Copyright (C) 2020 Bautista and Krishnan. This is an open-access article distributed under the terms of the Creative Commons Attribution License (CC BY). The use, distribution or reproduction in other forums is permitted, provided the original author(s) and the copyright owner(s) are credited and that the original publication in this journal is cited, in accordance with accepted academic practice. No use, distribution or reproduction is permitted which does not comply with these terms. 